\title{
Índia em transformação: o novo crescimento econômico e as perspectivas pós-crise
}

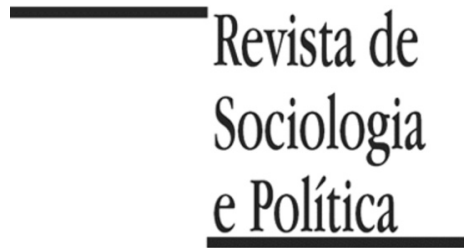

DOI: $10.1590 / 1678-987314225006$

\author{
Arindan Banik e Fernando Padovani
}

\begin{abstract}
RESUMO
O objetivo do artigo é sistematizar dados e informações recentes sobre a economia indiana, no sentido de caracterizar o contemporâneo modelo de crescimento indiano, aqui chamado de "novo crescimento", avaliando suas fontes, lógicas, setores e atores, bem como sua inter-relação com setores específicos da sociedade indiana, como as estruturas sociais, o Estado e o setor público, a agricultura e o mundo rural, e, ainda, sobre as dinâmicas de inserção internacional. Essa sistematização visa averiguar as condições e perspectivas de sustentabilidade econômica do modelo de crescimento em curso, considerando também os desafios imediatos colocados pela crise financeira internacional. A análise aponta para a existência de condições concretas de sustentabilidade econômica do modelo indiano, baseada na perspectiva de expansão de seus setores dinâmicos, como o setor de exportação de serviços tecnológicos e de manufaturas destinadas ao mercado interno. Evoluções paralelas relacionadas à transição demográfica, à disponibilidade interna de poupança e de investimento, ao crescimento das novas classes médias, às perspectivas de continuidade de oferta de investimentos estrangeiros e de conexão com as cadeias produtivas globais, além da identificação de dinâmicas sociais de transformação e adaptabilidade, reiteram a existência de condições de sustentabilidade do atual modelo de crescimento. Entretanto, não se trata de uma sustentabilidade sem riscos, ao serem identificados também desafios de percurso importantes, como a tarefa de garantir-se a sustentabilidade financeira do Estado indiano e a consequente viabilização dos importantes investimentos em infraestrutura, educação e inovação, capazes de garantir as necessárias condições de estabilidade, absorção de mão de obra, crescimento equitativo, oferta de mão de obra qualificada e inovação, além de segurança alimentar. Essas tendências de adaptabilidade dialogam com as recorrentes interpretações elaboradas sobre a economia e a sociedade indiana que enfatizam seu extremo particularismo, focando aspectos como pobreza, arcaísmo, rigidez social, instabilidade política, diversidade cultural, entre outros elementos que dificultariam a mobilização da ação coletiva e a sustentabilidade do modelo de crescimento.
\end{abstract}

PALAVRAS-CHAVE: Índia; crescimento econômico; agricultura; setor público; transformação social.

Recebido em 28 de Agosto de 2013. Aprovado em 02 de Outubro de 2013.

\section{Introdução}

A economia indiana completou, em 2012, uma série ininterrupta de 20 anos com elevadas taxas de crescimento, compondo um seleto grupo de seis economias, ao lado de países como China e Vietnam. Desde o começo dos anos 1990, o país conhece taxas médias anuais de 6\%, passando para o patamar médio de $8 \%$ durante a primeira década do século XXI, o que garante o período de duas décadas com média de 6,8\%, o que representa um crescimento médio da renda per capita de $4 \%$ ao ano (Goi 2011). Mesmo durante os piores anos da recessão mundial, o crescimento médio indiano no período 2007-2009 manteve-se em 6,7\%. Esses indicadores econômicos fazem que a economia indiana seja comumente apontada como uma das prováveis superpotências econômicas antes da metade do século. Entretanto, a ponte que possibilitará a continuidade entre os animadores resultados de economia emergente verificados nos últimos anos e a realização da promessa de potência internacional pressupõe a superação de desafios importantes pela sociedade 
indiana, como diferentes tipos de gargalos e importantes custos de transação verificados no plano doméstico, desafios que são complementados ainda pelas incertezas trazidas pela conjuntura internacional pós-2008, marcada pela longa recessão dos países do hemisfério norte. Desafios domésticos e externos que podem colocar em risco a sustentabilidade do atual modelo de crescimento indiano.

Entre os tradicionais desafios encontrados no plano interno estão os grandes déficits de infraestrutura, a pesada burocracia estatal que dissemina custos e incertezas para o ambiente de negócios, especialmente relacionadas à estabilidade institucional e macroeconômica, como inflação elevada e riscos de sustentabilidade financeira do endividamento do setor público. Também são comumente apontados como eventuais limitadores do modelo de crescimento outros desafios bastante peculiares ao caso indiano, como os extensos segmentos da população afetados pela extrema pobreza e pela secular dívida social, as tensões políticas, sociais, étnicas, religiosas e comunitárias, ou até mesmo a existência de uma grande diversidade e complexidade cultural e regional, simbolizada pelo emblemático sistema de castas. Já no plano externo, os desafios relacionam-se com a sustentação tanto da oferta de capitais para investimento direto e para o financiamento da crescente dívida soberana quanto pela sustentação da demanda pelos serviços tecnológicos, o mais importante item das exportações indianas, uma vez que as economias do G-7, o principal mercado consumidor dessas exportações, têm sido severamente afetadas pela recessão mundial (Bhagwati \& Srinivasan 2002).

Entretanto, mesmo diante de tantos desafios, o crescimento vivido pela economia indiana parece sugerir a existência de processos de transformação e de adaptação capazes de pavimentar o caminho de continuidade do atual modelo. Essa hipótese de sustentabilidade não estaria ligada apenas à dimensão quantitativa de duração e intensidade do crescimento, mas especialmente à sua característica de renovação. Nesse sentido, o crescimento da economia indiana poderia ser entendido como novo, inédito e diferente. Inédito pelo fato de que, na história econômica moderna do país, desde o início do direct rule britânico, nunca ter sido registrado um surto de crescimento semelhante, em intensidade e duração, tratando-se, portanto, do maior boom da história econômica do país (Basu 2004; Roy 2000). Novo, por assentar-se sobre novas bases, sobre novos setores, sobre uma riqueza nova, e pressupor um novo padrão de inserção na economia mundial. Um modelo novo por ter como polo dinâmico o setor de tecnologia de informação (TI), por ser financiado por investimentos estrangeiros diretos (IED), em intensa conexão com as chamadas cadeias produtivas globais, e ainda por estar orientado para a exportação off-shore de serviços de TI, capaz de gerar cerca de $25 \%$ do total das exportações indianas. Esse setor tecnológico é altamente internacionalizado: cerca de $75 \%$ de suas receitas são geradas pelas exportações e é capaz de absorver $44 \%$ dos investimentos estrangeiros diretos que entram no país. Um setor que sozinho gera ao redor de 2,5 milhões de empregos diretos, representando 7\% do PIB (GOI 2011; Panagaryia 2008). Por fim, trata-se de um modelo que pode ser classificado como diferente, na medida em que se trata de um caso raro na literatura do desenvolvimento comparado onde o processo foi iniciado e continua a ser mantido pelo setor de serviços, sem passar, nessa fase de decolagem, pelo circuito manufatureiro (Singh 2003; Virmani 2002). O setor de serviços hoje representa 57\% do PIB indiano e 50\% das exportações do país, com vendas internacionais que atingiram US\$ 106 bilhões em 2008 (GOI 2011). 
Se a base desse novo modelo está no setor exportador de tecnologia, especialmente softwares, com grande participação de empresas transnacionais, outros segmentos dentro do setor de serviços contribuem em grande intensidade para o bom andamento do modelo, especialmente aqueles habilitados pela tecnologia de informação, tais como os serviços contábeis, as centrais de reservas, os célebres call-centers, serviços jurídico-legais, diagnósticos médicos, processos administrativos corporativos, chamados serviços de back-office, ou de $\mathrm{BPO}$, o business process outsourcing, que representam cerca de um terço das exportações do setor de serviços (GOI 2011).

É importante ressaltar a centralidade do investimento internacional e do comércio internacional para esse modelo. A rápida internacionalização do setor contribui para que a Índia seja, juntamente com China e Brasil, um dos maiores destinos de Investimento Externo Direto (IED) entre as economias emergentes, recebendo em média US\$ 25 bilhões por ano ao longo da última década, registrando a marca de US\$ 40 bilhões em 2009. E, da mesma maneira que as demais economias emergentes, a internacionalização da Índia acontece também na direção inversa, ao tornar-se um importante exportador de empresas multinacionais, com remessas de IED da ordem de US\$ 18 bilhões (Banik 2006; GOI 2011). No plano dos fluxos comerciais, a internacionalização também é acelerada, fazendo que a taxa de abertura da economia indiana ultrapasse o tradicional patamar de $15 \%$, atingindo atualmente o patamar de $40 \%$, nível elevado para padrões internacionais; nível elevado também para outras economias emergentes internacionalizadas, como a brasileira, com seus $22 \%$ (GOI, 2011). Especificamente no setor de serviços indiano, o nível de abertura alcança o elevado índice de $60 \%$. Essa renovada tendência de inserção internacional pode sinalizar uma maior integração da economia indiana com as cadeias produtivas globais, fazendo que o índice de participação acionária estrangeira nos 20 maiores grupos não financeiros atinja o patamar médio de $41 \%$. No ano de 2007, entre as 500 maiores empresas do mundo classificadas pela revista Forbes, cerca de $40 \%$ delas mantinham operações na Índia, seja por investimento direto, seja por relações de outsourcing (Capital Market 2004)

Mesmo fundamental para o setor de TI, a internacionalização mostra-se importante também para muitos outros setores da economia local, como sugere a análise da lista dos dez maiores exportadores indianos. Ali encontramos cinco empresas de tecnologia (Infosys, IPCL, Wipro, Satyam Computers e HCL), três do setor de siderurgia (Adani, National Aluminium e Jindal Iron), um farmacêutico (Rambaxy) e ainda a Tata Motors, automobilística (Capital Market 2004). No mesmo sentido, é interessante notar que, além de preponderante no setor de serviços de TI, o sistema de out-sourcing internacional revela-se importante também em alguns setores industriais e da manufatura, como no caso da indústria automobilística e dos têxteis. (Banik \& Bhaumik 2006)

Entretanto, apesar da grande importância da internacionalização para a sustentabilidade do crescimento como um todo, estimulando vários setores da economia e funcionando como elemento decisivo para a geração de riqueza, os setores ligados ao mercado consumidor doméstico, como o setor de bens duráveis, não são desimportantes, especialmente com a crescente ampliação de sua contribuição para o crescimento. Casos ilustrativos são os setores dos eletrônicos, celulares, eletrodomésticos, alimentos processados, construção civil e ainda a indústria de automóveis, com vendas anuais de um milhão de veículos apenas no mercado doméstico (CSO 2007). O mercado consumidor doméstico revela-se importante para todos os setores com melhor desempenho 
na economia indiana, inclusive para o próprio setor de tecnologia da informação, mas, especialmente, para os setores que produzem bens duráveis, como automóveis e motos, eletrodomésticos e eletrônicos, além das telecomunicações, aço e siderurgia e farmacêuticos. Esse crescente mercado interno é o foco prioritário para a maioria dos grandes grupos empresariais do país, como Ambani-Reliance, Tata, Bharti, Mittal, Birla (Hindustani Motors), Bajaj, DFL, Mahindra, Oberoi, Hero, Rambaxy, ICICI Bank ou Eicher (Capital Market 2004). Com uma classe média estimada de 200 milhões de pessoas, crescendo no mesmo ritmo da expansão do PIB, a Índia parece caminhar firmemente para tornar-se um país de classe média, constituindo-se em um dos maiores mercados consumidores do mundo. Atualmente, o país já possui maior número de lares classificados como de classe média do que de baixa renda (NCAER 2010).

Seja como for, e para além das razões conjunturais, como, por exemplo, a circunstancial exploração nichos de mercados internacionais ou de diferenciais de competitividade baseados na mão de obra qualificada de baixo custo, caberia investigar, em função do crescente debate, se o processo de crescimento indiano verificado ao longo das duas últimas décadas possui perspectivas de continuidade, ou seja, se possui condições estruturais para sua sustentação. $\mathrm{O}$ presente artigo pretende caracterizar o contemporâneo modelo de crescimento indiano, no sentido de identificar suas fontes, lógicas e dinâmicas características, seus setores e atores preponderantes, avaliando sua inter-relação com áreas específicas da sociedade indiana, como a cultura tradicional, o Estado e o setor público, a agricultura e o mundo rural, e ainda sobre as suas lógicas de inserção internacional.

Essa sistematização inicial visa oferecer elementos para a discussão sobre a sustentabilidade econômica desse modelo de crescimento, em função da perspectiva de expansão de seus setores dinâmicos, como o setor de exportação de serviços tecnológicos, complementado pelo setor de bens de consumo destinado às novas classes médias urbanas, mas também em função dos desafios de transformação das estruturas de mercado ou da agricultura, além dos desafios imediatos colocados pela crise econômica internacional iniciada em 2008.

Essas tendências potenciais de transformação e adaptação analisadas no presente artigo pretendem dialogar com as recorrentes interpretações baseadas no particularismo da economia e da sociedade indianas, interpretações que enfatizam aspectos como pobreza, desigualdade, arcaísmo, rigidez social, instabilidade política e social, extrema complexidade cultural, entre outros lugares comuns associados à sociedade indiana, elementos que poderiam dificultar a mobilização da ação coletiva no sentido da sustentabilidade de um modelo de crescimento sustentado em novos setores e numa nova inserção internacional.

A partir da revisão de literatura sobre a economia indiana, serão discutidas as condições gerais de sustentabilidade do modelo de crescimento atual a partir da avaliação de perspectivas setoriais, como o setor de exportação de tecnologia e do setor de produção de bens de consumo para o mercado doméstico. Além disso, seria importante avaliar outras perspectivas do ambiente econômico local, como a possibilidade de manutenção dos fluxos internacionais de investimentos e de internacionalização da economia, a disponibilidade de poupança interna e investimento, o aprimoramento das estruturas de mercado, o comportamento da agricultura como fator de disponibilidade de mão de obra e de alimentos e ainda o ambiente institucional e sua relação com o setor público. 
A análise aqui proposta pretende oferecer elementos para o crescente interesse a respeito da sustentabilidade do crescimento nas economias emergentes, que, no específico caso indiano, tradicionalmente apresenta graus adicionais de incerteza em função das características especiais do modelo, do peso das variáveis internacionais, e ainda em função da prosaica complexidade atribuída tanto às instituições como à estrutura da sociedade indiana.

\section{A sustentabilidade do modelo indiano na revisão da literatura}

\section{II.1. O setor de TI e a sustentabilidade do crescimento}

A discussão sobre a sustentabilidade de modelo de crescimento indiano tradicionalmente passa pela discussão da viabilidade do setor de exportação de serviços tecnológicos como setor dinâmico da economia. A controvérsia origina-se das experiências comparativas disponíveis na literatura da economia desenvolvimento, onde surtos de crescimento e "milagres econômicos" costumam ser tradicionalmente sustentados pelo crescimento do setor industrial (Acharya 2003; Moreira 2011). Essa discussão encontra-se bastante difundida no debate econômico indiano contemporâneo, inspirada pela preocupação quanto à sustentabilidade de longo prazo da contribuição do setor de serviços como setor dinâmico, o que afetaria o crescimento econômico como um todo (Singh 2003; Virmani 2002).

É interessante notar que a participação do setor de serviços na economia indiana sempre foi elevada, mas ela tem se tornado ainda mais importante depois de processo de liberalização e abertura iniciado pelas reformas de 1991. Nesses últimos 20 anos, o setor industrial (que inclui manufaturas, construção civil e refinarias) tem crescido a taxas mais discretas, com média anual de 5\%, mantendo praticamente inalterado seu peso relativo na economia nacional, sempre ao redor de um quarto do PIB. No mesmo período, a agricultura perde importância constantemente, passando do patamar de um terço para cerca de $20 \%$ do PIB (com taxa média anual de crescimento de 4\%), enquanto o setor de serviços passou de $30 \%$ para $45 \%$, números que não incluem os $10 \%$ do setor público (RBI 2007). O aumento da importância do setor de serviços relaciona-se, na verdade, com a transformação desse setor, transformação comandada pela notável performance do setor exportador de serviços tecnológicos e de engenharia, mas também pelo bom desempenho dos segmentos de serviços empresariais, telecomunicações e bancos, fazendo que o setor como um todo registre um crescimento médio anual de $10 \%$ ao longo dos últimos 20 anos. Seria esse componente tecnológico dentro do setor de serviços que estimularia tamanha contribuição para a economia, sendo responsável por cerca de 3 pontos à taxa percentual do crescimento indiano. Nesse contexto, pode ser considerado como o polo dinâmico que tem sustentado o crescimento elevado da economia indiana (Virmani 2002).

A exportação de serviços tecnológicos faz da Índia o maior exportador de softwares do mundo, dominando cerca de $20 \%$ do mercado mundial. Ao mesmo tempo, essa plataforma de exportação de serviços terceirizados por grandes companhias estrangeiras do setor de tecnologia, o célebre outsourcing, também tem se diversificado para outras áreas, os chamados serviços habilitados pela tecnologia de informação, como os serviços contábeis, as centrais de reservas, os serviços jurídico-legais, os diagnósticos médicos, os processos administrativos corporativos, chamados serviços de back-office, como tratamento 
de dados, ou ainda os call-centers (Srivastase \& Gelhaut 2003). Essa delocalização para o território indiano de serviços efetuados diretamente por subsidiárias de empresas multinacionais ou em formas de alianças com empresas terceirizadas indianas emprega $40 \%$ dos profissionais do setor de tecnologia, ou seja, um milhão empregos diretos (Datt \& Sundharam 2009). Essa tendência faz que, dos dez maiores exportadores indianos, cinco sejam companhias de TI: Infosys, TCS, Wipro, Satyam e HCL (CSO 2007).

A origem do fenômeno pode ser creditada à diáspora de engenheiros indianos para os EUA durante a "década perdida" de 1980, resultado de um aparente "sobre-investimento" realizado até então na educação superior no país (Basu 2004). Naquele momento, as empresas americanas de tecnologia, aproveitando a janela inicial da abertura econômica do país no governo Rajiv Gandhi, viabilizada pelas inovações em telecomunicações, vieram investir in loco na Índia, buscando "na fonte" o abastecimento em grande escala de mão de obra qualificada de baixo custo e sem barreiras de idioma (Brunner 1995; Srivastase \& Gelhaut 2003). Os investimentos em capital humano realizados teriam sido o pressuposto da arrancada econômica, que recebeu insumos complementares advindos de investimentos do governo para a criação de uma "zona de processamento de exportações de tecnologia" em Bangalore, associada em cluster de inovação com o Indian Institute of Technology (ITT) local.

A abertura do país aos investimentos estrangeiros vai acabar constituindose em condição necessária para a instalação de grandes plantas produtoras de tecnologia direcionadas às operações off-shore de transnacionais da informática (Basu 2004; Nagaraj 2003). Com o florescimento desse modelo, pode-se dizer que, atualmente, todas as grandes empresas multinacionais de tecnologia, sem exceção, possuem alguma etapa de seu processo produtivo ou administrativo sendo realizado na Índia. São atividades realizadas por subsidiárias realizadas com qualidade e motivação, por funcionários qualificados, em língua inglesa, custando, literalmente, um décimo dos valores vigentes na Europa e Estados Unidos (Reddy 2011).

\section{II.2. Manufatura de bens de consumo e sustentabilidade do crescimento}

Apesar da visibilidade do setor exportador de TI na economia indiana e apesar de certa maneira ofuscado pela exuberância do crescimento de outros setores manufatureiros do sudoeste asiático, outro importante elemento de sustentabilidade do modelo de crescimento indiano encontra-se no setor produtor de bens de consumo manufaturados e no potencial de crescimento do mercado doméstico.

Projeções recentes, como aquelas do "India Economic Survey Report 2010/11" (GOI 2011), apontam para a tendência de crescimento elevado e sustentado do setor manufatureiro e industrial a partir do ano de 2011, com taxas projetadas de $11 \%$, superando a elevada média anual de $10 \%$ verificada ao longo do período 2003-2008. Apenas os setores de automóveis e bens de consumo duráveis registraram crescimento de $26 \%$ no ano de 2010 , com destaque ainda para o renascimento do setor têxtil e dos alimentos processados. A construção civil também parece igualar sua elevada média anual de $12 \%$ verificada no período 2003-2008 (idem). Os dados de produção industrial na economia indiana podem até causar surpresa se não levarmos em conta o tamanho do parque industrial indiano, classificado pela Unido-ONU como o $9^{\circ}$ mais im- 
portante do mundo, maior inclusive que o brasileiro, atualmente classificado na $10^{\mathrm{a}}$ posição (Moreira 2011).

As condições de sustentabilidade do mercado doméstico indiano de bens de consumo manufaturado estão relacionadas, por um lado, ao crescimento do mercado consumidor e, por outro, à capacidade de promover o investimento produtivo. Um dos elementos decisivos para a sustentabilidade do modelo atual de crescimento indiano tem sido a elevada disponibilidade de poupança interna, que tem sido canalizada para o financiamento de investimentos produtivos e de formação de capital, especialmente para o setor manufatureiro, menos dependente do capital estrangeiro que o polo dinâmico do setor de serviços. A manutenção de uma baixa taxa de juros interna contribui para a efetivação desses investimentos, com taxas nominais de $8 \%$.

Como aponta Basu (2004), a tendência histórica tem sido a ocorrência de uma taxa de crescimento correspondente a um quarto da taxa de poupança interna disponível. O crescimento elevado estaria ocorrendo porque a taxa de poupança interna estaria elevando-se consistentemente, deixando o patamar de $20 \%$ do PIB verificado nos anos 1990 para o índice de 35\% apurado nos últimos anos (GOI 2011). Em correlação direta, constata-se que a taxa de investimento está subindo constantemente ao longo do mesmo período, passando igualmente do patamar de 20\% em 1990 para 38\% do PIB a partir de 2006 (idem). Para vários economistas indianos, estaria longe de ser uma coincidência o fato de que, ao lado de taxas elevadas de crescimento, a economia indiana apresenta hoje um dos índices mais elevados do mundo de investimento e de formação de capital (Bardhan 2008; Mohan 2008).

Teria sido justamente um panorama inverso, caracterizado por patamares reduzidos de poupança interna, fechamento a investimentos estrangeiros e reduzido nível geral de investimento, a explicação comumente apontada para os modestos índices de crescimento da economia indiana verificados durante os anos 1950 e 1970, um crescimento seguro mas modesto, variando ao redor de $2 \%$ ao ano, alcunhado popularmente como hindu rate of growth, bastante coerente com o patamar de poupança e de investimento de $10 \%$ do PIB disponível naquele período (Bardhan 2008; Virmani 2002).

Para outros economistas, esse nível de investimento é importante, mas de maneira indireta, pois, ao equipar a economia para uma produção maior, teria a capacidade de disseminar inovações provocando um spill-over tecnológico, aumentando assim a produtividade média da economia. Ou seja, seria o aumento tecnológico da produtividade a causa principal do crescimento econômico. Nesse sentido, estudos demonstram que a produtividade per capita da economia indiana tem melhorado, na ordem de 15\% entre 1997 e 2007 (Hsieh \& Klenow 2009; Moreira 2011). Além disso, estudos empíricos identificam uma correlação que é favorável para a Índia, no sentido de que quanto menor o nível de renda per capita da economia, maior tenderia a ser o impacto dos ganhos de produtividade dos investimentos, em função dos maiores retornos marginais possíveis em economias com menor nível estoque de capitais. $\mathrm{Ou}$ seja, quantidades similares de investimento e de inovação tendem a causar efeitos mais elevados sobre o crescimento quanto menor for a renda per capita do país (Hsieh 2009; Virmani 2002). A título indicativo, vale a pena recordar que, apesar dos significativos avanços registrados nos últimos anos, a economia indiana ainda hoje é classificada pelos critérios internacionais como um low income country, com uma renda per capita ao redor de US\$1 000, apenas a $75^{\circ}$ do mundo (Subramanian \& Kumar 2011). 
O debate sobre os motivos que causariam essa elevação significativa da taxa de poupança interna na economia tem se tornado cada vez mais popular no estudo das grandes economias emergentes. Talvez inspirado pelo sucesso do sistema chinês, nota-se um resgate de diagnósticos menos focados na eficiência alocativa do sistema de preços e mais atentos a fatores estruturais, como a disponibilidade interna de poupança, como determinantes do nível de investimento. Parece ser o caso do resgate promovido pelo Fundo Monetário Internacional da hipótese de Franco Modigliani, elaborada nos anos 1960, que defende que poupança interna e investimentos são funções do aumento do tamanho da população economicamente ativa e da propensão dessas populações para poupar e adquirir "bens indivisíveis de alto valor unitário", como a aquisição de imóveis ou o início de um novo negócio (IMF 2005). O chamado "efeito Modigliani" explicaria a correlação direta entre proporção de população produtiva existente e os níveis de poupança e de investimentos.

Tal distribuição demográfica geraria uma situação de "dividendo demográfico", por meio da qual muitas economias emergentes, como China e Índia, poderiam financiar mais facilmente seu crescimento por possuir elevados contingentes de população em idade economicamente ativa (dois terços na China). Processo semelhante, aliás, ao vivido por outras economias emergentes, como a Europa no século XIX, os Estados Unidos no início do século XX ou o Japão, após a II Guerra Mundial. Nesse contexto de transição demográfica, a economia indiana estaria, nos dias de hoje, apenas começando a desfrutar de seu "dividendo demográfico", que tende a tornar-se ainda mais intenso dentro de 30 anos, quando a atual população composta por $50 \%$ de jovens e crianças começarem a fornecer legiões de novos trabalhadores para o esforço social de produção. Estima-se que, a cada ano, 13 milhões de novos trabalhadores entram no mercado de trabalho indiano (idem). E essa seria uma das mais fortes razões da sustentabilidade do crescimento indiano, enquanto, no caso da China, ela já estaria perto de exaurir suas vantagens comparativas demográficas (Virmani 2002).

No caso indiano, haveria ainda outro fator demográfico que também condicionaria a competitividade e o crescimento da economia, ligado à taxa de migração urbana. A exemplo do que ocorre atualmente na China e em outras economias emergentes, novas e antigas, o valor da mão de obra rural pode encontrar-se extremamente reduzido em comparação com padrões internacionais, e a incorporação gradual dessas populações rurais ou marginalizadas aos processos produtivos conectados direta e indiretamente com a economia internacional poderia oferecer margens compensadoras e vantagens competitivas importantes para esses setores, em termos de redução de custos. A transição de mão de obra rural e marginalizada para os setores conectados com os mercados internacionais, a chamada migração inter-setorial de mão de obra, poderia oferecer tanto ganhos de produtividade importantes para estes setores produtivos quanto aumento de remuneração para os trabalhadores (IMF 2005; Srinivasan 2006).

A distribuição rural-urbana, que chegava a $90 \%$ de população rural nos tempos coloniais, chegou a 77\%, em 1981, e $72 \%$ em 2001. Os resultados do recente Censo de 2011 apontam para um índice de 59\% de população rural, o que caracteriza a década de mais intensa urbanização da história indiana (GOI 2011). O fenômeno é intenso nos estados de grande população do vale do Ganges, como Uttar Pradesh e Bihar, estados que concentram um sexto da população do país, com taxas elevadas de população rural, bem acima da média nacional, ligadas a uma agricultura empobrecida, em transição, tornando-se 
grandes celeiros de migrantes para as cidades. Resultado: ao lado das 600 mil aldeias, o país já conta com 40 cidades com mais de um milhão de habitantes (RBI 2007).

No cotidiano indiano, esses ganhos de produtividade inter-setorial podem ser observados sob a forma da intensa migração de jovens para as grandes cidades e pelo drama da migração circular das famílias que deixam por períodos determinados os campos indianos para buscar trabalho temporário, geralmente na construção civil, nas médias e grandes cidades. Essa ancestral prática da sociedade indiana tem se institucionalizado, sendo objeto de políticas ora assistencialistas, ora repressivas do poder público, refletindo a precarização do emprego rural (Gidwani \& Sivaramakrishnan 2004). A migração temporária é uma tradição secular na Índia, composta por grande trânsito sazonal de grupos de trabalhadores rurais para as cidades, tradicionalmente nos períodos de entressafra, seguindo as notícias de grandes obras públicas desde o tempo da Grand Trunk Road. Mas, nesses tempos da nova economia, a migração sazonal tem crescido consideravelmente. Embora seja difícil estimar esse movimento, pois os números dessa migração confundem-se com os dados da migração genérica, algumas estimativas apontam para que um sexto da população indiana, ou seja, 170 milhões de pessoas que se direcionam para as cidades a cada ano, com destaque para ocupações na construção civil, mas também para outras áreas rurais de agricultura comercial (Gidwani \& Sivaramakrishnan 2004; Jeyaranjan, Nagaraj \& Harris 2010).

Por fim, diante das incertezas sobre a capacidade, do setor de serviços, de absorver em grande escala a mão de obra em transição demográfica e geográfica, reitera-se a importância de crescimento robusto também do setor manufatureiro, tanto para absorver a mão de obra em transição quanto para evitar dinâmicas de desigualdade. Quanto mais dependente de setores intensivos em capital, como se verificou no Brasil e no México nos anos 1970, mais desigualdade deverá ser gerada, uma vez que o modelo tem capacidade de gerar muita renda mas limitada absorção de mão de obra. Já o crescimento puxado por setores intensivos em mão de obra, como se verificou em Taiwan e na Coréia nos anos 1970, tende a estimular maior absorção de mão de obra, provocando resultados com menos desigualdade, como aponta o célebre estudo comparativo de Ahluwalia, Chenery e Carter (1979).

Como em outros casos, também na economia indiana essa dinâmica de concentração e desigualdade provocada por um setor dinâmico intensivo em capital e tecnologia poderia ser minimizada no longo prazo através de uma "mudança estrutural", ou seja, a redistribuição e realocação da mão de obra e de fatores entre os diferentes setores da economia. Entretanto, essa realocação vai depender da rigidez de mobilidade existente entre os setores dessa sociedade, provocada por determinismos de casta ou ainda por baixos investimentos em educação. Isso porque a migração da mão de obra para os setores mais dinâmicos e remuneradores depende em grande grau da educação, mesmo quando efetuada por gerações diferentes. Elevados graus de rigidez provocariam baixos índices de repartição dos frutos do crescimento, provocando situações de "crescimento empobrecedor", como tem sido caracterizado por Bhagwati e Srinivasan (2002) desde o final dos anos 1950. 


\section{II.3. Estruturas sociais e sustentabilidade do crescimento}

Como sustentado anteriormente, as transformações quantitativas trazidas pelo vigoroso crescimento econômico verificado nas últimas décadas na economia indiana teriam a capacidade de também provocar transformações qualitativas no tecido social, tanto nas suas dinâmicas quanto nas suas estruturas. Entre essas transformações estariam, por exemplo, a expansão das relações de mercado no seio da sociedade, na modernização de instituições, o surgimento de novos setores de atividade e ocupações ou ainda ao aumento da mobilidade social e geográfica.

O debate sobre os efeitos do crescimento econômico sobre as estruturas sociais de mercado passaria pela tradicional discussão sobre a existência ou não, na sociedade indiana, de diferentes racionalidades econômicas ou de focos de rigidez social. Tanto para o debate envolvendo racionalidades diferentes quanto para os obstáculos à mobilidade social, mostra-se importante a discussão sobre a sobrevivência, em maior ou menor grau, do sentimento de identidade de casta e da família alargada.

Esse debate dialoga com toda uma tradição da análise social sobre a economia indiana, herdeira das análises de Louis Dumont e Max Weber, que consolidam a leitura de uma economia constituída por racionalidades diferentes, basicamente em função da presença determinante da família alargada e da identidade de castas. Para eles, essas resistentes estruturas impediriam que a sociedade indiana pudesse ser classificada como pertencente ao "universo do econômico moderno", uma vez que as relações de circulação e distribuição seriam condicionadas pelas representações de mundo tradicionais, e não por relações de mercado entre "individualidades anárquicas", tendo assim a capacidade de impor uma racionalidade econômica de outra ordem para as trocas e para a produção social (Dumont 1966). Essas estruturas de grande segmentação e hierarquização também contribuiriam para dificultar a mobilidade social ou a chamada transição inter-setorial que permitiria melhores oportunidades de repartição dos benefícios trazidos pelo crescimento.

Mais tarde, essa leitura seria reinterpretada pelos autores da economia institucional, que utilizariam o caso indiano como um dos paradigmas da ação coletiva limitada, ao caracterizar a sociedade indiana como fragmentada em diferentes racionalidades sociais e em diferentes lealdades, em diferentes "coalizões distributivas", o que constituiriam entraves eficientes para a mobilização da ação coletiva e, consequentemente, para a decolagem do processo do desenvolvimento econômico (Bhagwati \& Srinivasan 2002; Krueger 1975; Olson 1982).

De acordo com essa tradição, caberia investigar se ainda hoje, e de maneira relevante, as decisões econômicas, como aquelas tomadas nos momentos da concessão de crédito ou determinação de preço, seriam motivadas por critérios outros que não aqueles inspirados pela racionalidade e pela competitividade de mercado. As decisões influenciadas pelos critérios da reciprocidade e da solidariedade comunitárias (familiares, religiosas e de casta) seriam ainda preponderantes no cotidiano dos mercados locais? Uma hipótese plausível, ainda mais se considerarmos que $80 \%$ das 500 maiores empresas indianas podem ser classificadas como family business, com origem no ramo comércio, setor tradicionalmente ligado aos valores da família patriarcal alargada e da identidade de casta (Dutta 1997). 
Alternativamente, os clássicos estudos de Milton Singer sobre as fórmulas de combinação entre moderno e tradicional na sociedade indiana sugerem a hipótese de uma tendência de "compartimentalização", onde cada vez mais os valores da modernidade dominam o universo do trabalho e empresarial, enquanto os valores do universo tradicional permanecem restritos cada vez mais ao âmbito da família, no qual a esfera pública estaria sendo lentamente esvaziada das formas sociais ancestrais (Singer 1972). Uma pequena etnologia do cotidiano, analisando em que circunstâncias e em que temas os indianos utilizam, entre indianos, o inglês ou o hindi, poderia oferecer elementos ilustrativos para entender os critérios desta convivência administrada entre duas lógicas ou duas linguagens culturais.

Embora sempre presentes, as identidades e racionalidades comunitárias parecem estar sendo, cada vez mais, restringidas à esfera interna da atividade econômica, tais como nos critérios de contratação de mão de obra. Seria possível dizer que as castas influenciam da porta para dentro no contemporâneo universo indiano dos negócios. Entretanto, da porta para fora, na esfera pública do mercado, famílias e empresas parecem resgatar imediatamente a milenar tradição mercantil "hindustânica", adaptando-se com desenvoltura às modalidades globalizadas do cálculo econômico.

Outras dinâmicas podem ser catalogadas por meio da revisão do debate, tais como a indicação da tensão entre absorção e resistência de relações sociais inspiradas pela modernidade (Acharya 2007), ou mesmo em função da reelaboração em termos modernos das formas ancestrais (Dirks 2001). Entre os elementos que explicitariam essa tensão podem ser citadas as mudanças em relação à participação da mulher na esfera pública, a fragmentação da tradicional estrutura da família patriarcal alargada, especialmente na dimensão da moradia (Ahuja 1993), ou ainda as posturas críticas por parte dos segmentos urbanos e educados em relação a certas tradições e práticas culturais, classificadas como arcaicas, reafirmando indiretamente valores de convergência com a modernidade ocidental, tais como secularismo, cientificismo, racionalismo, transparência, entre outros.

Além das explicações centradas na compartimentalização e na tensão, algumas abordagens enfatizam a hipótese do esvaziamento, como aquelas que trabalham com os impactos dos movimentos de urbanização, de aumento da classe média urbana, de mobilidade social, movimentos capazes de gerar relativização dos critérios identitários como, por exemplo, os sentimentos de solidariedade de casta, de comunidade, de religião, de língua e de região, estimulando a ocorrência forçada de novos padrões de convivência e interação social. Os novos padrões de mobilidade e convívio tornariam tais identidades menos mobilizadoras nas relações sociais, cedendo espaço para outros tipos de identidade e de discriminação, como a identidade de classe, de formação profissional, de renda ou de nível educacional. Nessa perspectiva, na Índia contemporânea de crescimento acelerado, essas cores que não se misturam podem parecer irresistivelmente profanadas pela intensificada circulação econômica e social, impondo convivências, embaralhando demarcações e fazendo que, por exemplo, o sentimento de pertencimento de casta e o cuidado ritualístico, cada vez mais, acabem por ou esvaziar-se ou retrair-se para o domínio da esfera privada. Segundo estimativa de Ahuja (idem, p. 209), atualmente cerca de $50 \%$ da nova classe média urbana é constituída por pessoas de castas inferiores. Uma situação bem diversa da encontrada na Índia pós-independência, quando cerca de $80 \%$ dos funcionários públicos pertenciam às castas mais altas. 
Entretanto, ao mesmo tempo, é possível detectar movimentos de resgate e reinvenção da solidariedade de casta, aplicada a novas situações e contextos, talvez com o sentido de uma reação "polanyiana" às transformações aceleradas. Um dos exemplos seria a disseminação de políticas afirmativas elaboradas a partir do critério da identidade de casta, o que tem estimulado iniciativas de institucionalização das comunidades, como organizações de cooperativismo e de autoajuda baseadas na identidade de casta, com o intuito de maximizar os benefícios do populismo de castas (Mishra 2006). Ao mesmo tempo, mesmo relativizada por muitas transformações, é possível identificar a identidade de casta como um dos determinantes do capital social inicial do indivíduo, ditando ainda sua estrutura de oportunidades. Vários outros indícios identificáveis na vida cotidiana indiana podem sugerir a resistência dessa forma ancestral de organização social, como a forte presença da instituição dos casamentos arranjados, a visão fortemente estratificadora das relações sociais, a relação do cidadão indiano com o espaço público (entendido como um espaço de ninguém, ou seja, como um espaço daqueles que são ninguém) ou ainda a segregação espacial das cidades (Ahuja 1993).

Ou seja, a ancestral forma de identidade da casta, readaptando-se para integrar-se a processos e finalidades modernas, como se fosse "um espectro do passado ajudando a construir a modernidade indiana" (Dirks 2001, p. 18). As páginas dos jornais indianos estampam diariamente esse dualismo entre esvaziamento e reinvenção das racionalidades tradicionais. Em um mesmo exemplar, enquanto, na seção de anúncios matrimoniais, atesta-se insistentemente a persistência das demarcações de casta, na dos empregos e de editais públicos essa permanência é explicitamente questionada, reiterando-se a irrelevância de quaisquer outros critérios de seleção que não aqueles vinculados à competência e à qualificação profissional.

Todos esses debates poderiam ser classificados como o processo da produção da modernidade indiana pelos próprios indianos, e à sua maneira. Nesse sentido, é preciso certa cautela de não reproduzir a nostalgia orientalista, a clássica nostalgia romântica ocidental em relação à Índia, percebida desde fora como mística e estática, nostalgia que sempre acaba inspirando sentimentos de surpresa e crítica face às transformações sociais e culturais produzidas pelos próprios indianos, que reivindicam a modernidade, ou que, pelo menos, são capazes de imaginar seu próprio mundo composto por transformações, negociando, no curso do processo, os termos de adaptação e de atualização das estruturas ancestrais e da tradição (idem). Um processo que se iniciou bem antes das reformas liberais de 1991, uma vez que o nacionalismo indiano, desde a independência, antes de representar um contraponto ao colonialismo britânico e ocidental, teria representado, pelo contrário, a continuidade da modernização ocidental por outros meios, como sugere a tradicional tese de Chatterjee (1993).

\section{II.4. O setor público e a sustentabilidade do crescimento}

Um dos curiosos efeitos indiretos do surto de crescimento econômico e de mudança de "regime de crescimento" a partir da abertura dos anos 1990 tem sido a considerável ampliação da capacidade de financiamento internacional do Estado indiano. Aliada à tendência de superliquidez vigente nos mercados financeiros internacionais e associada ao panorama de juros baixos na Europa, Japão e Estados Unidos, o que torna o investimento financeiro nos mercados 
emergentes bastante atrativo, encontra-se consideravelmente facilitada a tarefa de financiamento dos governos emergentes.

No caso indiano, essa situação contribui para mais afrouxamento da disciplina fiscal do governo e para a perpetuação de um elevado déficit público, um desafio histórico para a gestão pública indiana, em função da presença de uma extensa burocracia estatal e da sempre pesada participação do Estado na economia, que percorre muitas atividades produtivas e amplas áreas regulatórias, mas também iniciativas de bem-estar, de segurança social e de políticas redistributivas e compensatórias, como subsídios e benefícios, destinadas a apoiar uma sociedade com tantas dívidas sociais históricas. Além disso, não se pode deixar de constatar a sempre pesada presença de um aparato militar e de segurança nos compromissos orçamentários do Estado indiano, que embora mantenha-se estritamente no patamar de $10 \%$ dos gastos públicos, cresce quase que de maneira indexada ao crescimento econômico, permitindo, assim, que os gastos militares totais dobrassem em termos reais entre 2006 e 2010, atingindo a cifra de 20 bilhões de dólares (GOI 2011).

A existência de uma constante pressão fiscal, conjugada com a facilidade de endividamento internacional, estimula o governo indiano a financiar uma parte elevada de suas atividades mediante empréstimos, fazendo que, na média dos últimos anos, cerca de $40 \%$ das despesas do Estado sejam financiadas pela emissão de títulos, e $60 \%$ pela tributação. $\mathrm{O}$ aspecto positivo desse apetite internacional pelos títulos de economias emergentes é que o governo indiano tem aproveitado a oportunidade para alongar sua dívida, trocando o financiamento de seu déficit por títulos com vencimentos de prazo maior e com juros fixos (Acharya 2007).

$\mathrm{O}$ risco do endividamento elevado ameaça a sustentabilidade financeira do setor público desde os anos 1980, exatamente um dos principais motivos das reformas de 1991, conduzidas pelo primeiro-ministro Narasimha Rao e pelo então ministro das finanças, Mammohan Singh (Krueger 2003). Entretanto, mesmo com os constantes esforços de ajuste fiscal, o déficit público, tem permanecido em elevados patamares, atingindo novamente o pico de $10 \%$ do PIB no ano de 2010, fruto, entre outros fatores, do aumento nos gastos com subsídios (especialmente para a gasolina, alimentos, fertilizantes e energia elétrica), custeio operacional de uma inchada máquina pública, aumento da folha salarial do funcionalismo (e mais seus amplos benefícios) e, finalmente, recrudescimento do serviço da dívida pública (GOI 2009; Sood 2010). Entretanto, graças a exitosos esforços recentes de equilíbrio fiscal, o déficit fiscal regrediu para os patamares de $8 \%$ e 7\%, nos respectivos exercícios fiscais de 2011 e 2012, graças particularmente ao crescimento da arrecadação e à diminuição dos subsídios à gasolina.

Com esses ajustes, o crescimento do endividamento do governo passou a ser menos preocupante, embora ainda elevado, na ordem de 69\%. Um índice superior, por exemplo, ao patamar do início da reforma orçamentária em 1991, quando a dívida pública representava 55\% do PIB. Após dez anos de diminuição, em 2001, os indicadores de endividamento retornaram ao patamar de 54\% do PIB, crescendo a partir de então para $69 \%$, em 2004, e finalmente para $74 \%$ em 2010, seu ponto mais alto na história (GOI 2009; GOI 2011). Um índice bastante elevado, mesmo para padrões das grandes economias emergentes, nas quais o nível médio de endividamento do setor público gira ao redor de $37 \%$ (GOI 2009). 
A discussão sobre o endividamento tem seu foco na questão da sustentabilidade da dívida, ou seja, na capacidade dos governos continuarem endividando-se, por meio da manutenção sustentada da procura pelos títulos públicos, o que, por sua vez, depende da credibilidade, tanto em relação à performance fiscal quanto aos demais fundamentos macroeconômicos. Nesse contexto, o otimismo reinante em relação às perspectivas da economia indiana tem gerado, no debate político-econômico doméstico, a popularização da tese deficitsdon't-matter, ou seja, o sentimento de que a manutenção de um grande déficit fiscal não representaria, em si, um problema, desde que ele possa continuar a ser fácil e amplamente financiado pelo endividamento. Entretanto, com a crise financeira mundial de 2008, sombras de incerteza começam a pairar sobre a validade da estratégia fiscal indiana, especialmente sobre a sustentabilidade da dívida, face ao risco de uma retomada forçada dos gastos públicos ou a um súbito redirecionamento dos capitais para os mercados americanos, atraídos pela retomada do crescimento. $\mathrm{Ou}$, ainda, face ao nervosismo de investidores internacionais diante de sinais de deterioração adicional dos indicadores das finanças públicas indianas, como aumento do crescimento do peso do serviço da dívida, que já representa um terço das receitas orçamentárias e que já registra uma taxa média de crescimento de cerca de $20 \%$ ao ano ao longo dos últimos dez anos (Sood 2010; Reddy 2011).

No que se refere à participação do Estado na economia, é interessante notar que as reformas de 1991, de liberalização e desregulamentação, acabaram sendo mais modestas e cautelosas do que se costuma afirmar, com um cuidadoso processo de privatização, mantendo-se sempre um patamar mínimo de participação acionária em todas as empresas públicas privatizadas e com a presença de estatais nos principais setores produtivos (Bardhan 2004). Também no que se refere ao ritmo, pode-se dizer que as privatizações indianas foram mais lentas até mesmo que aquelas ocorridas na China (Moreira 2011). Em alguns setores, como bancos, petróleo e gás, mineração, energia elétrica, a participação estatal é predominante, chegando a $70 \%$ no caso do setor bancário e financeiro, dominado por bancos comerciais com controle acionário do Estado (Kapila 2008). As empresas estatais indianas são responsáveis por $40 \%$ do emprego da economia formal, $76 \%$ do estoque de capital fixo e $67 \%$ da produção industrial (CSO 2007). Entre as dez maiores empresas indianas figuram, com destaque, as quatro gigantes estatais, a ONGC (Oil and Natural Gas Company), estatal do setor de petróleo e gás e maior empresa do país, seguida pelo o State Bank of India, pela Indian Oil e ainda pela Indian Railways (GOI 2010). O crescimento econômico elevado, aliado a tradições nacionalistas e de promoção do bem-estar, antes de minimizar essa importante participação do Estado, parecem fortalecer o modelo de "capitalismo de Estado" em moda em todas as grandes economias emergentes.

Além disso, o governo central possui uma estrutura administrativa minuciosa, contando, por exemplo, com 55 ministérios, incluído ministérios como o Ministério dos Fertilizantes, dos Assuntos Tribais, do Carvão, dos Assuntos Corporativos, das Indústrias de Alimentos Processados, das Minorias, da Gestão Participativa (Panchayati Raj), e ainda o Ministério do Aço, das Pequenas e Médias Empresas, da Justiça Social, dos Têxteis e ainda o Ministério das Ferrovias, que supervisiona a estatal Indian Railways, que sozinha emprega 1,5 milhão de funcionários. Nesse contexto, não poderia faltar um ministério para cuidar dos interesses do próprio funcionalismo, o Ministério do Funcionalismo Público (GOI 2010). 
A participação dos subsídios merece uma nota à parte na análise do orçamento do governo. Os subsídios que permaneceram no patamar de $0,5 \%$ do PIB entre 1994 e 2002 passaram para 3\% no período 2008-2010. Também em termos reais, o crescimento dos gastos com subsídios é evidente, triplicando os valores destinados entre 2004 e 2010, passando de 90 para 290 bilhões de dólares (GOI 2011), com destaque para a energia elétrica, fertilizantes e alimentos, além dos urgentes subsídios à gasolina e diesel concedidos, no auge da crise, com o objetivo de combater a alta internacional do barril de petróleo, revertendo, pela primeira vez, a política de não intervenção nos preços dos combustíveis lançada em 2002 (Reddy 2011). Os tradicionais subsídios à eletricidade, fertilizante e alimentos são sempre de difícil controle, além de resistentes aos ajustes, em função da forte tradição da política eleitoral baseada no assistencialismo e do populismo eleitoral, especialmente no plano da política estadual (Bardhan 2004; Jenkins 1999; Shukla 2008).

A equação federalista indiana está conjugada com a chamada fragmentação regional da política, que coloca grandes desafios para equilíbrio fiscal, pois os governos estaduais são inclinados a manter suas clientelas políticas locais financiadas por políticas públicas populistas, pressionando os orçamentos estaduais, que acabam demandando tanto repasses da união como também, e em larga escala, emissão de títulos públicos estaduais (Bardhan 2004; Shukla 2008). Apesar da contribuição dos impostos regionais, a arrecadação é, em linhas gerais, bastante centralizada na união, controlada por movimentos políticos de alcance nacional (como o Congress Party ou o Janata Party), gerando certa tensão em relação aos gastos destinados a atender compromissos localistas da política estadual, via de regra, controlada por partidos de oposição com forte base local (Shukla 2008). O maior equilíbrio orçamentário de 2011-2012 parece ter sido garantido mais pelo significativo aumento da arrecadação do que por níveis mais satisfatórios de coordenação política e fiscal entre os governos da união e dos estados.

Recentemente, o aumento da participação dos gastos e investimentos em infraestrutura no orçamento do setor público parece sinalizar a inadiável retomada da ampliação das infraestruturas, tais como em aeroportos, portos, eletricidade, rodovias, ferrovias e telecomunicações, na tentativa de reverter os gargalos preocupantes para a sustentabilidade do crescimento da economia como um todo. Os novos investimentos em infraestrutura procuram superar a tradicional "doença fiscal indiana", segundo a qual o permanente desequilíbrio fiscal acaba comprometendo os investimentos públicos (Kapila 2008). Entretanto, essas políticas representarão uma nova pressão sobre o Orçamento da União, a menos que sejam operacionalizados esquemas alternativos de financiamento, como aqueles baseados nos estímulos fiscais para empreendedores privados ou as parcerias público-privadas (Reddy 2011).

\section{II.5. Agricultura e sustentabilidade do crescimento.}

Entre as tendências presentes no chamado novo crescimento, aquelas que influenciam de maneira mais imediata o universo rural e a economia agrária foram os processos concomitantes de abertura internacional e de desregulamentação interna dos mercados, semeados a partir de 1991 e que segue dando frutos depois da virada do século. Com o aumento mundial dos preços agrícolas e diante do aumento da renda disponível nos mercados domésticos, a agricultura indiana começa a receber estímulos vindos de fora de seu universo, basicamente na forma de rendimentos adicionais, demanda adicional por ali- 
mentos e demanda adicional por trabalhadores. Essas tendências combinadas provocam a elevação dos preços ao produtor, a valorização dos salários rurais (Nagaraj 2010) e, ainda, a melhoria de cerca de $18 \%$ dos termos de troca entre produtos agrícolas e manufaturados, entre 1982 e 2000, em favor dos produtores rurais (Kapila 2008; Acharya 2003). Pode-se, assim, dizer que, com o atual processo de crescimento, a renda está sendo redistribuída em favor do campo.

Um fator que tem contribuído para essa dinâmica tem sido a liberalização dos preços e dos canais de comercialização pelo governo, em um grau até surpreendente, tendo em vista o tamanho da população empregada no campo, 600 milhões de pessoas vivendo em 600 mil pequenas aldeias. Toda estruturada fundamentalmente a partir dos mercados locais, os mandis, essa comercialização já se faz quase integralmente de maneira não controlada e a partir de preços de mercado flutuantes, alinhados aos preços internacionais, e não mais controlados pela Food Corporation of India (Datt \& Sundharam 2009). Nessa mesma direção, no final de 2011, foi superado um tradicional ponto de resistência regulatória, ao ser autorizada a participação de investidores estrangeiros no setor de supermercados, o que poderá estimular a montagem de cadeias produtivas agrícolas, comandadas pelos varejistas, o que reduziria o número de intermediários no mercado de alimentos. Pode-se dizer que todas essas reformas liberalizantes têm contribuído para a expansão das relações de mercado e um grau mais elevado de monetarização nas trocas sociais e para o surgimento de novas ocupações e atividades no seio da economia agrícola.

A liberalização dos mercados agrícolas coincide com a convergência entre preços domésticos e preços internacionais em elevação, causando preocupação entre consumidores urbanos (e governantes) ao pressionar bastante a inflação. Mas, do ponto de vista dos produtores rurais, essa elevação de preços tem causado uma melhoria sensível da renda (Kapila 2008), mesmo levando-se em conta a ainda reduzida taxa de abertura da agricultura indiana, estimada em $10 \%$, em 2006, com exportações da ordem de nove bilhões de dólares, em 2008 (GOI 2011). Da mesma maneira, apesar de todo processo de liberalização, restrições de mercado ainda existem, como limitações da participação do capital estrangeiro em muitas atividades agrícolas ou para a aquisição de terras, ou da inexistência de um setor de agro-business na intensidade que se conhece no Brasil.

Entretanto, no contexto do debate sobre a sustentabilidade do crescimento, e especificamente sobre o papel que a agricultura indiana poderá desempenhar nesse processo, especialmente na capacidade de produzir alimentos para a crescente urbanização, existe uma discussão interessante sobre a pequena capacidade de resposta do mundo rural indiano, ou à "inelasticidade" de oferta. Uma das características que intriga os estudiosos da agricultura indiana referese precisamente aos discretos impactos causados pela elevação de preços ao produtor sobre o nível de produção. Apesar dos dados que apontam para um claro aumento de renda dos produtores, a resposta esperada em termos de aumento de produção não tem sido significativa, fazendo que o setor agrícola cresça a taxas bem mais modestas do que os demais setores da economia indiana. A partir dos pressupostos clássicos da racionalidade econômica, o aumento de remuneração representaria um incentivo para novos investimentos e maior produção. Entretanto, o que se tem verificado na última década é uma resposta apenas modesta ao estímulo representado por preços ao produtor consideravelmente melhores (GOI 2011). Mesmo no que se refere à produtividade média no campo, os índices praticamente não se alteraram desde os anos 1980, final da tendência de evolução contínua, fruto da "revolução verde" de Indira Gand- 
hi, verificando-se, a partir de então, estabilização e até ligeira queda nos últimos anos, especialmente a partir do ano 2002. Nas três cultuas alimentares mais importantes do campo indiano, arroz, trigo e lentilha, a taxa média de crescimento da produtividade permanece insistentemente ao redor de $1 \%$ ao ano, ao longo das últimas duas décadas (GOI 2011; Kapila 2008).

Entre as hipóteses mais comumente levantadas para explicar essa baixa reatividade a preços por parte da agricultura indiana estão os gargalos de acesso a transporte, comunicação, financiamento, irrigação, eletrificação e fertilizantes, mas também gargalos nas cadeias de comercialização, dominada de maneira importante por intermediários e atravessadores (Mohan Rao \& Storm 1999; GOI 2011). Até Amartya Sen, em antigo estudo sobre a abertura da agricultura indiana (Sen \& Nayyar 1994), já previa que os potenciais benefícios da abertura e desregulamentação, tais como alinhamento aos preços internacionais, poderiam provocar efeitos apenas limitados sobre a produção do campo indiano, em função exatamente da falta de infraestrutura. Nessas circunstâncias, a abertura e a desregulamentação dos mercados agrícolas só seriam produtivas se fossem complementadas por políticas de disseminação de irrigação, estradas, fertilizantes e créditos. A presença do Estado no campo indiano pode mostrar-se efetiva ao disseminar o crédito ou promover obras de grande escala em infraestrutura, especialmente na irrigação, substituindo mutirões comunitários e poderes locais (Mellor 1988). O crédito tem se tornado mais acessível por meio da atuação do Nabard (National Bank for Agriculture and Rural Development), da mesma maneira que a disseminação de esquemas de leilões eletrônicos, para a disseminação de informação sobre preços mundiais e nacionais para as instâncias locais de comercialização (Jeyaranjan, Nagaraj \& Harris 2010).

Além da irrigação e do crédito, questões como transporte e informação também são importantes. $\mathrm{O}$ acesso da produção originaria das aldeias ao mandi local, o centro de comercialização localizado em cidades pequenas e médias, onde a produção é comprada pelos dalals, os intermediários locais, a preços flutuantes de mercado (e não mais fixados pela Food Corporation of India), depende agora diretamente das condições de informação sobre preços e de escoamento pelas precárias estradas rurais indianas. Uma vez negociada nos mandis, a produção é revendida a varejistas e moinhos. Toda essa operação envolve perdas e custos elevados devido às condições ruins de transporte, de acesso aos mercados locais e de informações sobre preços. O encurtamento da cadeia produtiva agrícola entre o consumidor urbano e os portões do produtor rural, com a eliminação dos muitos intermediários envolvidos no processo, pode aumentar o impacto das elevações dos preços nacionais e mundiais (GOI 2011; Datt \& Sundharam 2009).

A presença de culturas de subsistência também se revela como outro elemento que dessensibiliza a produção em relação às variações de preço, especialmente nas culturas de arroz no sul do país, baseadas em pequenas propriedades e no trabalho comunitário familiar (Jeyaranjan, Nagaraj \& Harris 2010; Singer 1972). Sintomaticamente, a célebre "revolução verde" indiana dos anos 1960-1970 teve como base precisamente o eixo Punjab-Haryana, justamente regiões de baixa ocorrência de agricultura de subsistência e de predomínio da chamada agricultura moderna. Nas vastas planícies irrigadas do norte da Índia, como o estado do Punjab, terra dos empreendedores agricultores sikhs, fortemente organizados em cooperativas comerciais; terra dos grandes projetos de irrigação, com sua estrutura fundiária baseada em grandes propriedades, regularizadas com títulos de propriedade, com a existência de um mer- 
cado de terras, empregando elevada taxa de fertilizantes e com boa presença de mecanização, fizeram do norte da Índia uma das mais extensas áreas cultivadas do planeta e o grande celeiro agrícola da Índia (Datt \& Sundharam 2009). Coincidência ou não, foi ali que também ocorreram as melhores respostas em termos de aumento de investimento, embora, em termos de crescimento da produção, a resposta também tenha sido modesta. Nas áreas de agricultura moderna, os investimentos agrícolas privados dobraram em termos reais entre 1982 e 2000, dados que contribuem para fazer da Índia um dos maiores produtores mundiais de arroz (18\% do mercado mundial), de chá (10\% do mercado mundial, embora em 1990 fosse de 22\%), trigo, cana de açúcar e especiarias (Kapila 2008).

Outro elemento que pode ser considerado para entender o problema da inelasticidade de oferta no campo seria a situação de limitação física de crescimento da área cultivada, devido ao esgotamento das terras disponíveis para cultivo na região de agricultura intensiva, Punjab e Haryana. Essa é, aliás, uma das características da agricultura indiana, o elevado índice de terras aráveis já ocupados e as reduzidas possibilidades de expansão da superfície cultivada. Sintomaticamente, a área cultivada não cresce na Índia desde o final da "revolução verde", no final dos anos 1970 (GOI 2011; Narain 1990). Para tal realidade, pode estar contribuindo a clara tendência de fragmentação da estrutura fundiária em curso no campo indiano, onde as grandes propriedades estão fracionando-se, causa e consequência do esvaziamento da influência dos $z a$ mindars, os senhores locais proprietários da terra. O tamanho médio das propriedades tem diminuído sistematicamente ao longo das últimas décadas, caindo pela metade desde os anos 1970, passando hoje para 1,4 hectares. (CSO 2007; Kapila 2008).

Sem terras novas para a expansão, o aumento de produção pode advir apenas do aumento do estagnado hindu yeld, da taxa de produtividade das terras já utilizadas, uma situação que complica o panorama geral, marcado ainda por pequena reatividade aos preços em elevação, gargalos de infraestruturas e escassez de terras. Além da estagnação dos investimentos públicos em irrigação, eletrificação, transporte e fertilizantes, uma hipótese que pode explicar a estagnação da produtividade agrícola está ligada à possível influência negativa exercida pelos subsídios. A quebra da produtividade aconteceu precisamente no momento em que se registrava uma forte retomada da política de concessão de subsídios, que se multiplicou por cinco em termos reais no período 20022008. Essa política, que Acharya (2007) chama de "populismo agrário" poderia ser uma das causas da paralisação da produtividade, estimulando que produtores adotassem a lógica racional de redução de esforços em lugar da lógica de aumento de rendimentos.

Entretanto, uma ressalva deve ser feita sobre a inelasticidade agrícola em questão, pois a comparação com outros setores de alta performance da economia indiana, que apresentam taxas médias de crescimento de dois dígitos, como serviços, indústria ou construção civil, pode provocar a percepção distorcida de que o setor agrícola está estagnado. Segundo apurado pelo India Economic Survey Report - 2010/11, se descontados os dois anos de recuo causados por uma seca de proporções históricas nos anos de 2009 e 2010, o crescimento da agricultura indiana mantém média de crescimento anual de 4,5\% nos últimos anos, índice que representa, no entanto, a sua média mais alta da história (GOI 2011). 
A relação da Índia com o resto do mundo tem sido historicamente marcada por um forte nacionalismo e por desejos de autonomia, com uma postura conservadora no que se refere a concessões quando das negociações internacionais, em matérias que vão do comércio à proliferação de armas nucleares (Narlikar 2009; Panagariya 2008). Diante dessa verdadeira tradição de política externa, a Índia acabou por consolidar-se como uma liderança dos países em desenvolvimento, no Movimento de Países Não-Alinhados, nas negociações comerciais, e do sistema monetário internacional. Da mesma forma, o país tem se mantido à margem dos regimes nucleares, não assinando o Tratado de Não Proliferação de Armas Nucleares. Uma tradição que se origina antes mesmo da independência política, quando se consolida a percepção no debate indiano sobre o papel ameaçador das potências ocidentais, especialmente a britânica, em relação às pretensões indianas de projeção e segurança, percepção capaz de inspirar uma desconfiança duradoura em relação a atores internacionais, em primeira pessoa ou em relação ao avatar político ocidental na região, o Paquistão. Uma duradoura percepção de um sistema internacional enviesado, bastante inspirada por variações da teoria da dependência e do nacionalismo, que é capaz de produzir um surpreendente grau de consenso interno entre os diferentes setores da burocracia estatal, entre os diferentes partidos políticos que se sucedem no poder e entre os diferentes setores da opinião pública doméstica (Narlikar 2009).

Essa forte tradição nacionalista na cultura política indiana tem sido capaz de, por exemplo, preservar políticas de elevado protecionismo comercial ou inspirar posicionamentos bastante assertivos nas mais diversas arenas das negociações internacionais (Kumar, Debroy \& Karmakar 2007), como se repetiu por ocasião de negociações de 2008 da Rodada de Doha, quando as negociações da OMC chegaram a um impasse especialmente em função das divergências entre Estados Unidos, e seus desejos de manutenção de subsídios agrícolas, e a Índia, demandante de critérios mais flexíveis para a aplicação das salvaguardas de importação de produtos agrícolas (Narlikar 2009). As tradicionais posições nacionalistas tem sido reinterpretadas por meio de um certo sentimento de autoconfiança, inspirado pelo ganho de poder relativo experimentado pelo país ao longo da última década.

Entretanto, os efeitos positivos do novo modelo de crescimento, um modelo fortemente apoiado na inserção internacional, têm impacto sobre vários setores da sociedade indiana, o que pode contribuir para um redimensionamento da relação da sociedade indiana com o resto do mundo. Nesse sentido, a Índia parece buscar uma redefinição da sua conturbada relação com os Estados Unidos, apoiando a ocupação do militar do Afeganistão, com grande engajamento na esfera de ajuda técnica para a reconstrução do país e sustentação do governo de Kabul. A diplomacia de Nova Délhi também tem concordado em aderir a certos princípios internacionais mínimos sobre a não proliferação atômica, assinando, em 2010, um acordo bilateral com os Estados Unidos em matéria de energia atômica.

No que se refere especificamente à relação com os países BRICS e, em especial, com o Brasil, nota-se um potencial de complementaridade tanto econômica como estratégica. Com a China, apesar de todos os traumas não digeridos em relação às disputas fronteiriças e relativas à segurança estratégica regional, o país tornou-se, em 2009, o maior parceiro comercial da Índia, suplantando os Estados Unidos, que é o maior destinatário das exportações de 
serviços indianos, desenvolvendo importantes conexões econômicas e corporativas com a China, como no caso no setor de TI, mineração, eletrônicos e automóveis. Com a Rússia, preserva a sólida parceria de muitas décadas, tanto no plano político-estratégico como no plano do comércio de armamentos e petróleo. Já o comércio bilateral com o Brasil revela-se ainda bastante tímido, com transações que representam apenas $1 \%$ das exportações de cada país. Somente no ano de 2005, a Índia entrou pela primeira vez na lista dos 25 principais parceiros comerciais do Brasil, ano em que foi assinado o acordo preferencial entre a Índia e o Mercosul. As exportações brasileiras concentram-se no item material de transporte (autopeças e vendas da Embraer), açúcar, etanol e óleo de soja. As atuais discussões de liberalização ao capital estrangeiro do setor açucareiro indiano trazem boas perspectivas para investimentos brasileiros. Já as exportações indianas concentram-se ao redor do petróleo $(51 \%)$, produtos químicos, têxteis e produtos farmacêuticos.

Para a dinâmica de consolidação dos BRICS, a Índia pode contribuir para a consolidação do grupo, com seus ganhos relativos de projeção internacional, advindos da boa performance econômica durante os anos de crise financeira internacional, consolidando-se como um dos polos de crescimento da economia mundial. Isso pode contribuir para um maior alinhamento de interesses do agrupamento para as negociações sobre a necessária reengenharia dos regimes multilaterais.

\section{Algumas discussões sobre a sustentabilidade do crescimento}

Como demonstra a revisão de literatura, o debate sobre a sustentabilidade do modelo de crescimento indiano está focado nas perspectivas de manutenção dos seus setores dinâmicos, a saber, o setor exportador de TI e o setor de bens de consumo para o mercado doméstico. Para isso, procura avaliar os desafios gerais existentes no ambiente econômico, como a adaptabilidade das estruturas sociais, o equilíbrio financeiro do setor público e a efetividade de suas políticas e instituições, a capacidade de resposta da produção agrícola e ainda aspectos ligados à economia internacional, como a demanda por produtos indianos e a oferta de capitais para investimento local.

No que se refere ao setor de exportação de TI, a literatura parece oferecer elementos indicativos sobre a capacidade desse setor de permanecer como a principal fonte de estímulos para o crescimento da economia indiana como um todo. Como caracterizado, trata-se de um setor com amplas conexões com os mercados internacionais, tanto pela demanda de serviços como pela oferta de capitais. Nesse sentido, as perspectivas de sustentação existem, uma vez que a demanda internacional por serviços tecnológicos tende a recuperar-se na mesma velocidade da retomada do crescimento nos principais mercados consumidores de TI, Estados Unidos, Inglaterra e Alemanha, já a partir de 2013. Apesar do resistente impasse nas negociações da OMC e do movimento universal de retomada do protecionismo, as perspectivas de crescimento do comércio internacional de serviços existem e parecem estar mais ligadas aos movimentos reais de internacionalização das empresas e das sociedades do que às negociações intergovernamentais em matéria de política comercial. Essa razão explicaria por que a taxa de crescimento do comércio de serviços sempre tem sido mais elevada que o crescimento do comércio de mercadorias na economia contemporânea. O comércio internacional de serviços deve continuar sua trajetória de crescimento também em função da disseminação das tecnologias de informação, que transforma uma imensa gama de serviços em 
itens comercializáveis internacionalmente. Isso pode fazer que, no longo prazo, a composição do comércio internacional inverta-se e acompanhe o perfil de distribuição verificado no interior das economias nacionais de renda média e elevada, onde preponderam os serviços.

Além dos importantes aspectos externos, a discussão da sustentabilidade do setor de serviços de TI como motor da economia indiana também deve levar em consideração o debate sobre o novo papel da economia do conhecimento no crescimento econômico, especialmente sobre o seu efetivo potencial de criação de riqueza, assumindo a função de "indústria" baseada no conhecimento, no sentido de atividades produtivas capazes de gerar valor novo, riqueza nova, mesmo sem conexão com a produção material, a produção física de bens tangíveis (Pedersen 2008; Srivastase \& Gelhaut 2003). Nesse sentido, as contradições de um modelo de crescimento puxado pelo setor de serviços seriam apenas aparentes, uma vez que a atual contribuição do setor não teria a mesma natureza daquela aportada pelo tradicional setor de serviços indiano de raízes coloniais, baseada na elevada participação do setor público e do comércio (Singh 2003).

Mesmo do ponto de vista dos custos dos serviços produzidos na Índia, a competitividade parece ainda assegurada por cerca de 20 anos, em função do ritmo lento de encarecimento da mão de obra tecnológica no mercado doméstico indiano. O diferencial de custos da mão de obra indiana, atualmente estimado como dez vezes inferiores aos padrões salariais vigentes nas economias da OCDE (Reddy 2011) ainda permitiria uma margem de competitividade prolongada, ao assumirmos uma taxa de melhoria no salário real indiano semelhante à taxa de inflação atual, hoje no elevado patamar de $10 \%$ ao ano.

Da mesma maneira que o setor de TI indiano aproveitou a janela de oportunidade representada pela grande oferta de engenheiros de bom nível, com domínio da língua inglesa, conjugada com a possibilidade de acesso a esse contingente pelas grandes empresas mundiais de tecnologia (Brunner 1995), a manutenção da oferta constante de mão de obra qualificada na área de tecnologia seria um requisito fundamental para a sustentação do crescimento do setor. Nesse sentido, o governo indiano parece bastante atento para esse desafio, investindo na formação de um elevado contingente de profissionais qualificados na área tecnológica, da inovação e da gestão, como demonstram os indicadores sobre o número total de engenheiros formados anualmente, na casa de $500 \mathrm{mil}$, como também os crescentes investimentos no fortalecimento de institutos de excelência, como os IIT e IIM. Uma estratégia que revoluciona o paradigma tradicional, permitindo economias emergentes competirem também na mesma área de vantagem comparativa dos países da OCDE, nas atividades de alto valor agregado das engenharias.

Coerentes com essa evolução poderiam ser classificados os esforços em curso no país, por parte de empresas e governos, no sentido de estimular a inovação e de reposicionar a oferta de serviços tecnológicos indianos em atividades com maior valor agregado, como design e tecnologias avançadas, tornando menos preponderantes as atividades operacionais intensivas, situadas nas partes inferiores das cadeias de valor (Panagaryia 2008).

No que se refere ao setor das manufaturas de bens de consumo orientadas para o mercado doméstico, as projeções otimistas de crescimento sustentado relacionam-se tanto com as perspectivas de crescimento do mercado consumidor doméstico como com as perspectivas de sustentação dos níveis de investimento produtivo. No plano do consumo, o crescimento da renda, do poder de 
compra e do tamanho dos mercados consumidores caminha em paralelo com o crescimento das classes médias urbanas indianas, que representam cerca de 200 milhões de pessoas. Esse contingente, que deverá constituir-se em pouco mais de uma década em um dos cinco maiores mercados consumidores do mundo, representa uma consistente fonte de demanda para os produtos do segmento de bens duráveis, como automóveis, motocicletas ou eletrodomésticos, como também para eletrônicos e celulares, além da construção civil.

Pelo lado da oferta, parecem consistentes os sinais de manutenção dos níveis de poupança interna e de investimento no patamar entre $35 \%$ e $40 \%$ ao longo da próxima década, segundo estimativas do Reserve Bank of India (RBI 2007), muito em função da elevação geral de renda como também do chamado "dividendo demográfico", potencializado ainda pela acelerada taxa de urbanização. Se mantida a histórica relação indiana de quatro por um entre investimento produtivo e crescimento da produção, esses elementos conjugados sinalizariam uma próxima década animada por taxas de crescimento da ordem de $10 \%$. Por outro lado, no que se refere à produtividade, tanto as tendências passadas, na qual se verificou ao longo de toda a última década um crescimento real médio de $1,5 \%$ ao ano da produtividade per capita, quanto às perspectivas futuras de realização de elevados investimentos governamentais e privados na inovação e na educação, sugerem uma melhoria na capacidade de assimilar e transmitir inovações trazidas pelos investimentos estrangeiros.

Entre os desafios que se colocam frente ao setor, podem ser listados a pouca flexibilidade do mercado de trabalho, gerador de muita informalidade, e também os gargalos em infraestruturas, como de transporte e logística internacional, mas especialmente a questão da eletricidade indiana, uma das grandes ameaças à sustentabilidade do atual modelo de crescimento, em função dos constantes "apagões" e do custo elevado, mais precisamente a sexta mais cara energia elétrica do mundo. Não deixa de ser sintomático que cerca de $40 \%$ das empresas estrangeiras instaladas na Índia possuam seus próprios esquemas de produção de eletricidade (Moreira 2011).

Ao mesmo tempo, um eventual cenário de falta de investimentos em inovação e em educação, combinado com perda de encarecimento dos fatores, pode deixar a economia indiana despreparada para o esgotamento dos padrões atuais de produtividade e de retorno dos investimentos. Nesse cenário, a economia indiana se veria presa na armadilha da renda média, o middle income trap, deixando de ser competitiva nos segmentos intensivos em mão de obra sem tornar-se competitiva nos segmentos intensivos em tecnologia. A Índia já parece enfrentar dificuldades de concorrência frente aos produtos manufaturados intensivos em mão de obra barata vindo da China, ou agora, do Vietnã e Camboja, o que pode comprometer o processo de criação de empregos pelo setor. Isso comprometeria também a capacidade de absorção de mão de obra na economia como um todo, além de gerar dinâmicas de desigualdade (Banik \& Bhaumik 2006).

No que se refere às estruturas sociais de mercado e sua relação com o processo de crescimento, como sistematizado na revisão da literatura, é possível supor que poucos elementos podem efetivamente vir a constituir-se em entraves ao processo de crescimento. As estruturas e dinâmicas sociais tão características da sociedade indiana, nos domínios das instituições, mobilidade, mercados, ocupação e racionalidade econômica, parecem capazes de operar funcionalmente diante dos novos estímulos vindos das relações de mercado em expansão sem gerar entraves ou racionalidades contraditórias. A identifica- 
ção de tendências de adaptação, compartimentalização, reelaboração e esvaziamento das lógicas e identidades ancestrais parecem contribuir para a constituição de uma esfera pública cada vez mais animada pelos critérios de mercado e do consumo. A hipótese de compartimentalização, como trabalhada por autores como Milton Singer e Ram Ahuja, pode oferecer uma hipótese interessante para o entendimento da complexa convivência entre dinâmicas ancestrais e contemporâneas no processo de construção da modernidade indiana.

Dentre todos os desafios enfrentados pelo setor público indiano para a sustentabilidade do crescimento, seja na sua dimensão institucional, regulatória, da eficiência das políticas públicas, os mais importantes parecem estar relacionados com a sustentabilidade financeira do Estado, que pode facilmente comprometer o ambiente macroeconômico, influir o financiamento de todas as demais políticas públicas e até ameaçar o modelo baseado em forte estatismo. Em um ambiente de crise financeira internacional, a disponibilidade de financiamentos pode efetivamente tornar-se uma questão bastante sensível, provocando tanto otimismo e relaxamento fiscal, como aconteceu até 2011, quanto, ao contrário, preocupação e fuga para a segurança, como tem acontecido a partir de 2012, aumentando consideravelmente o risco de sustentabilidade financeira da dívida pública. Para isso, a capacidade de ajuste fiscal permanece como uma das questões centrais da sustentabilidade do modelo indiano, uma questão que passa inevitavelmente pelo complexo desafio de redefinição da equação federalista indiana. Na relação Estado e sociedade, além do dilema fiscal, outros fatores institucionais e regulatórios também encarecem os custos de transação no ambiente de negócios indiano, tais como uma legislação trabalhista complexa e dispendiosa, a lentidão da justiça, a precariedade da garantia e exigibilidade dos contratos, além de uma penosa burocracia estatal, entremeada por práticas cotidianas de corrupção.

Para realizar o grande potencial da agricultura indiana, e para que ela possa responder às grandes demandas impostas por um modelo de crescimento internacionalizado e urbano, a superação dos gargalos de infraestrutura e de produtividade deverá ser enfrentada com urgência, melhorando a capacidade de resposta da agricultura indiana. O país com o maior percentual de áreas cultiváveis dentro de seu território e também com a maior área irrigada do mundo dá continuidade a uma tradição agrícola secular, que desde os tempos ancestrais conhece uma grande produção, o que possibilitaria a existência de grandes populações nas planícies do Ganges, e que, mais tarde, viria garantir a autossuficiência alimentar desde o começo dos anos 1970. Hoje, apesar de ser o segundo produtor mundial de arroz, trigo, chá e cana-de-açúcar, a Índia, entretanto, ocupa apenas a $77^{\mathrm{a}}$ taxa mundial de mecanização e a $52^{\mathrm{a}}$ de produtividade, com índices um terço inferiores aos da China (Kapila 2008).

Diante da perspectiva de continuidade da elevação mundial dos preços agrícolas, poderá ser mantida a tendência de melhoria dos rendimentos do produtor, desde que sejam ampliadas as reformas que tornem mais efetiva essa transmissão, reduzindo os muitos e muito bem consolidados intermediários e atravessadores instalados entre o produtor, os mercados rurais (as mandis) e o consumidor final. Com pequena margem para o crescimento das terras cultiváveis, a agricultura indiana necessita de uma segunda "revolução verde", baseada em pesquisa agronômica mas também em grandes investimentos públicos que ofereçam melhor acesso a transporte, eletrificação, irrigação, crédito e fertilizantes. A alarmante alta da inflação dos alimentos nos mercados indianos pode sem dúvida ser creditada à convergência entre preços domésticos e internacionais, mas também reflete uma situação estrutural de desequilíbrio entre a 
oferta estabilizada de alimentos e a fortalecida demanda doméstica, vinda dos consumidores indianos com mais renda.

Finalmente, as dinâmicas de inserção internacional, que certamente contribuíram fortemente para o modelo de crescimento indiano ao longo das duas últimas décadas, tendem a ser mantidas e mesmo ampliadas. A participação dos investimentos estrangeiros no setor de serviços tecnológicos e a abertura do comércio internacional, elementos decisivos para a criação do novo polo de riqueza, gerando spill over de renda, de inovação tecnológica e de produtividade para os demais setores da economia, podem contribuir para, progressivamente, relativizar os tradicionais ideais nacionalistas dentro do debate cultural indiano.

Se a percepção positiva dos efeitos trazidos pela inserção internacional vier a tornar-se claramente preponderante, seria possível imaginar uma discreta redefinição da estratégia geral na relação da Índia com o resto do mundo, inspirado por um grau um pouco maior de pragmatismo, tanto no plano das burocracias e dos tomadores de decisão como na opinião pública, inspirando novos posicionamentos nas áreas de segurança, energia nuclear, comércio e investimento, sem deixar de lado a reivindicação de uma maior participação nas estruturas de decisão e de coordenação da economia internacional (Narlikar 2009).

Essas dinâmicas fizeram ainda que a Índia aumentasse sua participação em todos os setores da vida internacional, como nos fluxos de investimento, de mercadorias e serviços, bem como na constituição de importantes reservas internacionais, atualmente o $4^{\circ}$ maior estoque do mundo, avaliado em US\$ 300 bilhões em 2012 (GOI 2011). Nesse sentido, é possível identificar iniciativas de maior colaboração com as potências ocidentais nos conflitos regionais e um maior desejo de cooperação com os Estados Unidos, em que pese a necessidade de revisão da anacrônica posição americana junto ao Paquistão.

\section{Conclusões}

Desnecessário reiterar aqui a importância do debate sobre o alcance limitado do conceito de crescimento econômico, fenômeno essencialmente quantitativo e contábil, focado no ritmo de variação do PIB e não necessariamente no ritmo de melhoria do bem-estar da sociedade ou do nível de desenvolvimento humano. Entretanto, processos intensos e prolongados de crescimento, como o verificado na Índia, onde a renda per capita dobra a cada década e o PIB triplica a cada 15 anos (Datt \& Sundharam 2009), podem provocar impactos qualitativos. Mesmo que apropriado de maneira concentrada e desigual, e mesmo que produza efeitos limitados para fazer desaparecer o grande estoque de dívidas sociais, a nova riqueza gerada ao longo dessas duas últimas décadas é pervasiva, provocando efeitos observáveis em todos os meandros cotidianos da vida social indiana. Até mesmo a legendária pobreza indiana tem regredido substancialmente segundo todos os indicadores ao longo do período, coerente com o quadro geral de transformações. Segundo os dados do PNUD, a Índia conheceu a $3^{\text {a }}$ mais elevada taxa de crescimento do IDH do mundo entre os anos 1980 e 2010. Entretanto, a história econômica comparada demonstra que modelos de crescimento que não são baseados em setores intensivos de mão de obra tendem a estimular a desigualdade. Embora as grandes dívidas sociais possam ser prioritárias e mitigadas por um crescimento intenso que efetiva- 
mente diminui a pobreza, no longo prazo, a desigualdade pode trazer dificuldades para os critérios de legitimação e de coesão social.

Seja como for, atravessando transformações quantitativas e qualitativas, é possível afirmar que a Índia sai bastante fortalecida do período de crise mundial, em termos absolutos e relativos. O país desfruta de uma projeção internacional mais significativa em todos os segmentos da vida internacional, tornando-se um dos principais pontos de referência para o crescimento da economia internacional, que cada vez mais passa a apoiar-se em outros pilares. Além disso, existem perspectivas reais de continuidade do crescimento, em função, por exemplo, das boas perspectivas de expansão de seu setor dinâmico, a exportação de serviços tecnológicos, sempre secundado com intensidade por um setor manufatureiro, orientado para o mercado doméstico e produtor de bens duráveis. Um segmento que certamente desfrutará de um mercado interno em expansão e também de crescente disponibilidade de investimentos produtivos, gerados pela transição demográfica vivida pela Índia.

Entretanto muitos desafios permanecem no caminho, que poderão ser transpostos principalmente em função da capacidade de sustentabilidade financeira do Estado indiano, uma das variáveis mais críticas para a sustentabilidade do crescimento. O elevado ritmo de endividamento em curso, mesmo que protegido por um nível recorde de reservas internacionais, da ordem de US\$ 300 bilhões, pode gerar riscos em situações de instabilidade da oferta dos investimentos internacionais. Isso colocaria em risco também o financiamento de todas as tarefas vitais a cargo do Estado indiano, como os mais que necessários investimentos em infraestruturas, na educação e inovação, no fortalecimento das instituições, na melhoria das políticas públicas, no financiamento de uma segunda "revolução verde", entre outros. Serão essas tarefas estruturais conduzidas pelo Estado que permitirão, por exemplo, que o setor tecnológico indiano consolide sua mudança de patamar competitivo, especializando-se em atividades tecnológicas de alto valor agregado, fugindo assim do risco do middle income trap.

A primeira e constante questão, sobre a sustentabilidade ou não do modelo de crescimento indiano, como visto, pode ser respondida com um otimismo vinculado, ao identificar elementos concretos de sustentabilidade, mas estariam condicionados a uma série de fatores, como a capacidade de sustentabilidade financeira do setor público e das reformas conduzidas pelo Estado nas áreas da educação, infraestrutura, inovação, agricultura e da estabilidade institucional. Ou, ainda, da capacidade de seu setor dinâmico, o setor de serviços tecnológicos, absorver toda a transição demográfica da Índia. Ou da capacidade, do setor manufatureiro, de complementar esse modelo de geração de riqueza e de absorção de mão de obra. Caso contrário, mesmo que a exportação de tecnologia possa continuar produzindo riqueza nova, que se dissemina indiretamente para todos os demais setores da economia, esse modelo estaria fadado a produzir desigualdade e resultados limitados.

Arindam Banik (arindambanik@imi.edu) é PhD em Economia pela Delhi School of Economics (Índia) e é professor do International Management Institute (Índia).

Fernando Padovani (fernando.padovani@espm.br) é doutor em Sociologia pela USP e professor da Faculdade de Administração e Finanças da Universidade do Estado do Rio de Janeiro (UERJ) e da Escola Superior de Propaganda e Marketing do Rio de Janeiro (ESPM-RJ). 


\section{Referências}

Acharya, S. 2003. India's Ecomomy. New Delhi: Academic Foundation.

2007. Can India Grow without Bharat? New Delhi: Academic Foundation.

Ahuja, R. 1993. Indian Social System. Jaipur: Rawat Publications.

Ahluwalia, M.; Chenery, H.B.; Carter, N.G. 1979. Growth and Poverty in Developing Countries. Journal of Development Economics, 6, pp. 299-341.

Banik, A.; Bhaumik, P.K. 2006. Foreign Capital Inflows to China, India and the Caribbean. London: Palgrave Macmillan.

Basu, K. 2004. India's emerging economy. Cambridge, MA: MIT Press.

Bhagwati, J.; Srinivasan, T.N. 2002. Trade and Poverty in the Poor Countries. The American Economic Review, 92(2), pp. 180-183.

Bhardan, P. 1998. The Political Economy of Development in India. New Delhi: Oxford University Press India. 2004. Disjunctures in the Indian Reform Process. In K. Basu, ed. 2004. India's Emerging Economy. Delhi: University of Oxford India.

2008. Some Reflections on Democracy and Political Economy of Development of India. In BID. India: Latin America's next big thing. Washington, D.C.: Inter-American Development Bank.

Brunner, H.P. 1995. Closing the Technological Gap: Technological change in India's computer industry. New Delhi: Sage.

Chaterjee, P. 1993. The Nation and Its Fragments. Oxford: Oxford University Press.

Datt, R.; Sundharam, K.P.M. 2009. Indian Economy. $9^{\text {th }}$ ed. New Delhi: S. Chand.

Dirks, N.B. 2001. Castes of Mind. Princeton: Princeton University Press.

Dumont, L. 1966. Homo hierarchicus: essai sur le système des castes. Paris: Gallimard.

Dutta, S. 1997. Family Business in India. New Delhi: Response.

Gidwani, V.; Sivaramakrishnan, K. 2004. Circular Migration and Rural Cosmopolitanism in India. In F. Osella, ed. Migration, Modernity and Social Transformation in South Asia. New Delhi: Sage.

Hsieh, C.T.; Klenow, P.J. 2009. Misallocation and Manufacturing TFP in China and India. Quarterly Journal of Economics, 224(4), pp. 1403-1448.

Jenkins, R. 1999. Democratic Politics and Economic Reform in India. Cambridge: Cambridge University Press.

Jeyaranjan, J.; Nagaraj, R.; Harris, J. 2010. Land, Labour and Caste in Politics in Rural Tamil Nadu. Economic and Political Weekly, 45(31), pp. 47-61.

Kapila, U. 2008. Indian Economy since Independence. $19^{\text {th }}$ ed. New Delhi: Academic Foundation.

Kumar, R.; Debroy, B.; Karmakar, S. 2007. India's Liberalization Experience: hostage of the WTO?New Delhi: Sage.

Krueger, A. O. 1975. The Benefits and Costs of Import Substitution in India.Minneapolis: University of Minnesota Press. , ed. 2003. Economic Policy Reforms and the Indian Economy. Chicago: University of Chicago Press.

Mellor, J. 1988. Food Production, Consumption and Development Strategy. In R.E.B. Lucas \& G.F. Papanek, eds. The Indian Economy. New Delhi: Oxford University Press India.

Mishra, P. 2006. Tentações do Ocidente. São Paulo: Globo.

Mohan, R. 2008. A Story of Sustained Savings and Investments. Economic and Political Weekly, 33(19), pp. 61-79.

Mohan Rao, J. \& Storm, S. 1999. Distribution and Growth in Indian Agriculture. In T.J. Byres, ed. The Indian Economy. New Delhi: Oxford University Press India.

Moreira, M.M. 2011. Índia: oportunidades, lições e desafios para as economias do Brasil e da América Latina. Rio de Janeiro: Elsevier.

Nagaraj, R. 2003. Foreign Direct Investment in India in the 1990s. Economic and Political Weekly, 38(17), pp. 1701-1712.

Nagaraj, K. 2010. Land, Labour and Caste Politics in Tamil Nadu in the 20th Century. Economic and Political Review Weekly, 45(31), pp. 47-61.

Narain, D. 1990. Studies on Indian Agriculture. Oxford: Oxford University Press.

Narlikar, A. 2009. Leadership and Change in the Multilateral Trading System. Leiden: Nijhof.

Olson, M. 1982. The Rise and Decline of Nations. New Haven: Yale University Press.

Panagaryia, A. 2008. The Emerging Giant. London: Oxford University Press.

Pedersen, J.D. 2008. Globalization, Development and the State. Basingstoke: Palgrave Macmillan.

Reddy, Y.V. 2011. Global Crisis, Recession and Uneven Recovery. New Delhi: Orient Blackswan.

Roy, T. 2000. The Economic History of India, 1857-1947. New Delhi: Oxford University Press India.

Sen, A. \& Nayyar, D. 1994. International Trade and the Agricultural Sector in India. In G.S. Balla, ed. Economic Liberalization and Indian Agriculture. New Delhi: ISID.

Shukla, P. 2008. Fiscal Federalism in India. In BID. India: Latin America's next Big Thing. Washington: Inter-American Development Bank.

Singer, M. 1972. When a Great Tradition Modernizes: an anthropological approach to Indian civilization. New York: Praeger.

Singh, N. 2003. Information Technology as an Engine of Broad-Based Growth in India. In P. Banerjee \& F.J. Richter, eds. The Knowledge Economy in India. Basingstoke: Palgrave Macmillan. 
Sood, A. 2010. Shadow-Boxing in Punjab on Government Finances. Economic and Political Weekly,45(24), pp. 22-26.

Subramanian, A.; Kumar, U. 2011. India Growth in the 2000s. Manila: Asian Development Bank.

Srinivasan, T.N. 2006. China, India and the World Economy. SCID Working Paper. Stanford Center for International Development.

Srivastase, A.; Gelhaut, S. 2003. Intangibles: Technology Trade in India. In P. Banerjee; F.J. Richter, eds. The Knowledge Economy in India. Basingstoke: Palgrave Macmillan.

Virmani, A. 2002. Sources of India's Economic Growth. Working Paper no. 131. New Delhi: Indian Council for Research on International Economic Relations-ICRIER.

\title{
Outras fontes
}

Capital Market. 2004. Compendium of Top 500 Companies in India - 2004. Mumbai: Capital Market.

CSO. Central Statistical Organization. 2007. Annual Survey of Industries, 2004-2005. New Delhi: Government of India.

IMF. 2005. World Economic Outlook. Washington, D.C.: IMF.

GOI. Government of India. 2009. Indian Public Finance Statistics 2009. New Delhi: Ministry of Finance.

GOI. Government of India. 2010. India 2010: A reference annual.New Delhi: Ministry of Information.

GOI. Government of India. 2011. Economic Survey 2010-2011. New Delhi: Ministry of Finance.

NCAER. National Council of Applied Economic Research. 2010. How India Earns, Spends and Saves. Report, July 2010. New Delhi.

RBI. Reserve Bank of India. 2007. Handbook of Statistics of the India Economy, 2006-2007. Mumbai: RBI.

\begin{abstract}
This paper aims to systematize recent data and information on the Indian economy, in order to characterize the contemporary Indian growth model, here called "the new Hindu growth". For this, it will be necessary to evaluate its source, its logics, main dynamic sectors and actors, as well its impacts on specific sectors such as the traditional society, the State and the public sector, agriculture and the rural society, and also the Indian foreign policy and its international insertion pattern. This interpretation aims to enquire the conditions and prospects for economic sustainability of this growth model, also considering the short term challenges brought by the international crisis. The analysis is based on updated data collected from reports and public documents produced by government and market institutions dedicated to the monitoring of the Indian economy, as well the various sectorial impacts of the new growth model. The analysis points to the existence of the concrete conditions of economic sustainability for the Indian model, based on the prospect of expanding their dynamic factors, such as the export from the technological services sector, the new urban middle classes, renewed market structures, the integration in global production chains, modernization of agriculture, in a clear perspective of transformation and adaptability. These identified trends dialogue with the common interpretations on the Indian economy and society emphasizing its "particularism" and diversity, what would make difficult to mobilize the collective action towards the sustainability of a growth model based on increasing international integration.
\end{abstract}

KEYWORDS: India; economic growth; agriculture; public sector; social change 